\title{
ADVANTAGES AND DISADVANTAGES OF QR CODE IN TAX INVOICES IN PORTUGAL
}

\author{
Anabela Marques ${ }^{1}$ \\ Leonilde Reis ${ }^{2}$
}

DOI: https://doi.org/10.31410/LIMEN.2020.167

\begin{abstract}
The systematization of the information underlying the electronic invoice, published in the Decree-Law no. 28/2019 of 15 February in Portugal, brought legislative changes leading to the introduction of a QR-Code on the invoice creating the conditions for the document's dematerialization. This article's purpose is to present the results of a set of surveys applied to the various stakeholders in the process, in order to validate the advantages and constraints of an aggregating Approach, designed to systematize such stakeholders in a process of this nature. The methodology adopted was Design Science Research and proved to be adequate for the design of the artefact. The elaborated approach and the results of the surveys are also presented. In 2021, invoices and other tax documents must contain a twodimensional bar code, containing all information related to the invoice, allowing the consumer to digitally send this information to his electronic invoice without his Fiscal ID introduction.
\end{abstract}

Keywords: $Q R$-code, Invoice, Innovation, Approach.

\section{INTRODUCTION}

lthough taxes are not the only source of tax revenue, they are undoubtedly the most
important, being hegemonic over the revenue from fines, fees, penalties, among others.
Tax evasion and fraud seriously undermine the economic and financial capacity of
governments, calling into question the principle of equity and tax justice (Marques, 2020).

The growing development of Information and Communication Technologies (ICT) that we have been observing in recent years, has been an accelerator of the digital transformation process of organizations. According to Secretaria do Estado dos Assuntos Fiscais - SEAF (2018), in this domain, Portugal has come to assume itself as one of the advanced tax administrations, being internationally recognized for its pioneering spirit and for the innovative projects that have followed the technological evolution and the digital transformation that has taken place in recent years. In Portugal, given the legal framework, tax-relevant invoices play a decisive role given the tax incentives granted to citizens when they request invoices.

Following the direction set by the Government to strengthen, simplify and digitalize the Public Administration (PA), and taking into account that the legislation related to invoices and other fiscally relevant documents was very dispersed, the Government, as a way to consolidate and update the legislation dispersed, proceeds to its regulation, through the Decree-Law no. 28/ (2019), of February $15^{\text {th }}$. Through this decree, the conditions for the issuance of paperless invoices are created, providing for the waiver of their printing.

Polytechnic Institute of Setúbal, Setúbal, Portugal

Polytechnic Institute of Setúbal, Setúbal, Portugal 
After the introduction of some changes associated with Electronic Billing in Public Procurement, it is pertinent to analyze the recent Decree Law 28/2019 of 15 February, alongside with other legislation regarding some more measures of the so-called "E-invoice 2.0" package, which will enter into force, at least according to expectations, throughout 2019 and 2022.

Through the implementation of the Decree Law no. 28/ (2019), and as of January $1^{\text {st }}, 2020$, invoices and other fiscally relevant documents must contain a two-dimensional bar code $(\mathrm{QR}$ Code), which will allow purchasers wishing to benefit from the collection deduction, to have the possibility of communicating to the Tax and Customs Authority-AT, invoices without a tax identification number, using the respective QR Code or the unique document code.

\section{IMPACT OF LEGISLATION}

According to Zhang (2018) the insertion of a QR-Code on the consumer invoice, is the solution for the company to make the technological connection between the company and tax authorities, allowing to streamline processes in a convenient, fast, and low cost way.

After the signing of a memorandum of understanding with the Troika and with the approval of the State Budget for the year 2012, the legislative authorization expressed in article no. 172 is born, so that the government can regulate a regime for the electronic transmission of the elements of the invoices (Melo, 2018).

In July 2012, the Government approved a structural reform of the billing regime in Portugal, which led to the start of the e-invoice system (Decree-Law n. ${ }^{\circ}$ 198/2012) production on January $1^{\text {st }}, 2013$. The participation of final consumers is the key to the success of the system and einvoice, a tax incentive for taxpayers that was created in 2013 due to the invoice requirement with its Tax Identification Number (TIN) (XXI Governo, 2015). This legislation introduced new rules for invoicing and filing for VAT taxable persons, creating the conditions for the existence of the paperless invoice. However, it is important to analyze what impact this legislation has on the different stakeholders.

A review of the literature regarding the subject's field was carried out, as well as the study of the legal diplomas, international standards, frameworks, and technological specifications in view of the specificity of the problem.

The Approach is a synthesis model that involves processes, people and technology, and allows to add knowledge contemplating the normative references related to this aspect, namely ISO/IEC 18004 (2015), and the ITIL V4 (ITIL, 2019), COBIT (ISACA, 2019), CMMI (CMMI Institute, 2019) frameworks.

The impact of the legislative change will lead to the availability, accessibility, and legibility of the relevant data and technical documentation to be guaranteed by the AT as well as the authenticity of the origin, integrity of the content, operational integrity, accuracy and reliability and legibility of the QR-Code (Decree-Law 28/2019).

With the dispensation of the goods transport document, the security and reliability will be guaranteed, which in return will allow the streamline of businesses, logistics or transportation processes and the increase of their efficiency. Furthermore, the possibility of integrating digital 
or scanned documents into the accounting software, the speed and efficiency of the accounting process and the reduction of the physical archive are equally expected to increase.

It also provides easy control of any transactions carried out by taxpayers in order to combat the informal economy, tax fraud and evasion, and the adoption of new technological instruments, thus incorporating a philosophy of innovation, debureaucratization, the dematerialization of documents, and saving resources. On the other hand, it compels the implementation of security measures (access, backup, management controls) and development of new technological aptitudes and tax incentives.

\section{APPROACH}

An Approach was created (Marques, 2020), with the aim to systematize the changes that the introduction of the QR-Code on the invoice can bring to the different stakeholders. According to Marques \& Reis (2020), the multidisciplinary and aggregating Approach enhances the systematization of the problem.

Figure 1. Approach - Stakeholders in the QR-Code

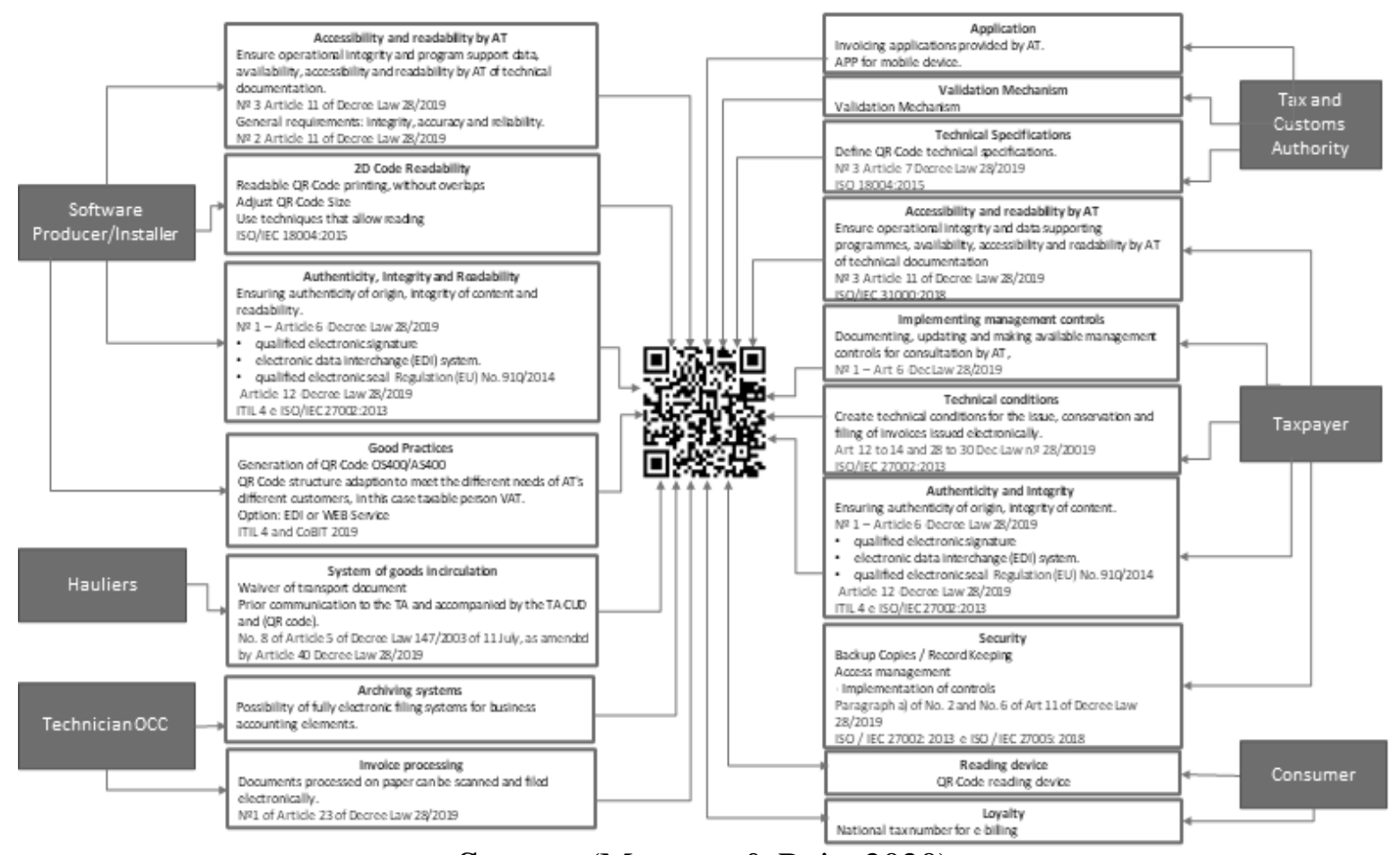

Source: (Marques \& Reis, 2020)

The Approach shown in Figure 1 was created, in order to systematize the different stakeholders in the process and allows stakeholders in the process to understand the differences and the development requirements and strategies to be followed to implement the QR-Code in the fiscal context and provide a tool to support decision-making and strategy development by helping to analyze the impact that changes will have on processes and to guide the development of appropriate measures and understanding of the issues involved in the decision (Marques, 2020). The underlying concerns in this area of the problem are ensuring the authenticity of the origin and the integrity of the content as well as the readability of tax-relevant invoices for the citizen. 


\section{ANALYSIS AND DISCUSSION}

It is considered that the added value of the Approach focuses on systematizing knowledge, centralizing, and synthesizing information, providing important conceptual bases for the theme and making available the main changes that the introduction of QR-Code will cause in a fastreading format, highlighting measures to be taken. Regarding the disadvantages of the approach, they focus on the fact that, as a result of the analysis of the data collection, it was found that information is not widely disseminated, and it is not possible to represent the interactions between the stakeholders in the approach.

The aim is to validate the approach drawn up, in order to analyze its suitability in practice. In view of this need, different types of the questionnaire were chosen according to the stakeholders in order to validate with experts the approach constructed. To this end, interview scripts were created, according to the profile of each actor, for subsequent analysis of content. Graph 1 briefly describes the number of interviews sent and the number of responses obtained.

Graph 1. Interviews sent and results obtained

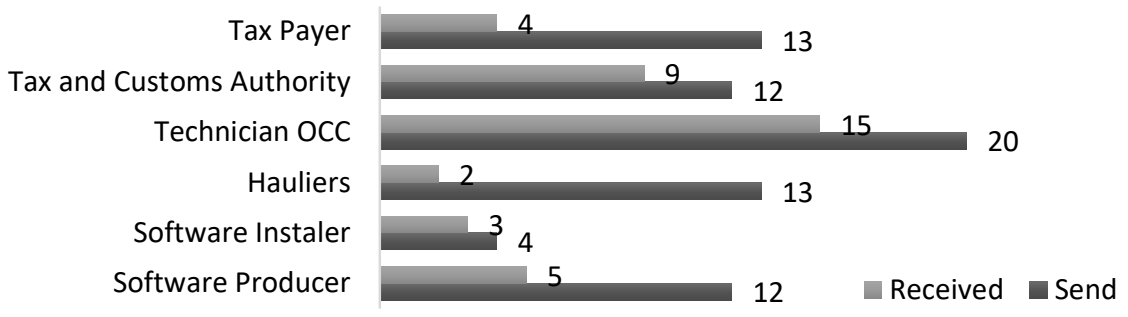

Through Graph 1 we can see that the highest number of results obtained Certified Accounting followed by the Tax and Customs Authority.

Following the analysis of the structured interviews, the existence of a common core between them highlights the need for a synthesis analysis of the interviews of the different stakeholders. In this sense, the data concerning the issues common to the groups analyzed, have been aggregated and analyzed, which we will present below.

In regard to the multiple-choice question, where it was requested that individuals indicate, from a common set of twelve advantages, those considered relevant with the introduction of the QRCode on the invoice, it was possible to observe the following answers as presented below in Graph 2.

Graph 2. Advantages of introducing QR-Code on the invoice

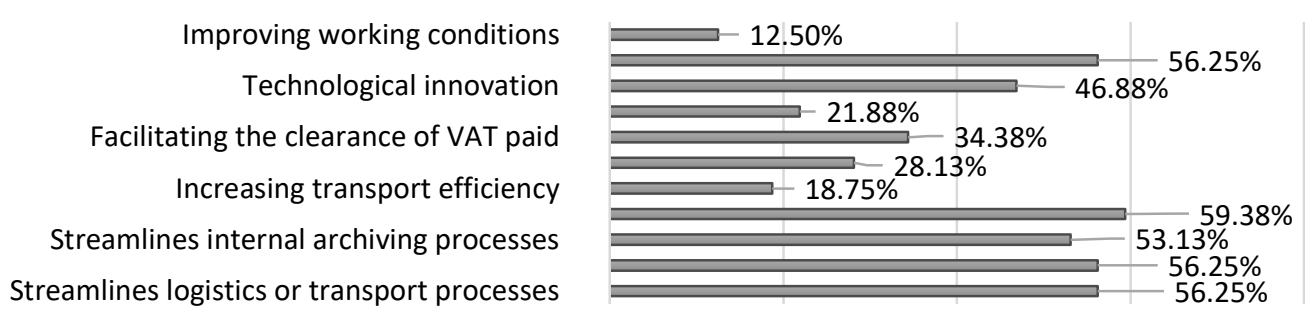

In an analysis of Graph 2, we can see that the advantages considered relevant for the respondents, are first of all the option "Assist in combating fraud and tax evasion" with 59.38\%, 
followed by "Integration of the documents produced by the invoicing program in the accounting software", "Streamlines the internal processes of filing, Streamlines the business processes and Streamlines the processes of logistics and transport "ex-aequo" with $56.25 \%$.

In regard to the multiple-choice question, where it was requested that individuals indicate, from a common set of five constraints, those that are expected to exist with the introduction of the QR-Code on the invoice, it was possible to observe the following answers as presented below in Graph 3.

Graph 3. Constraints you expect to exist with the introduction of QR-Code on the invoice

$$
\begin{array}{r}
\text { Licensing of new SW Versions } \\
\text { Installation of suitable printers } \\
\text { Development costs } \\
\text { Paper purchase costs } \\
\text { Purchase of equipment }
\end{array}
$$

Adaptation of PIF Invoicing Software that does not allow...

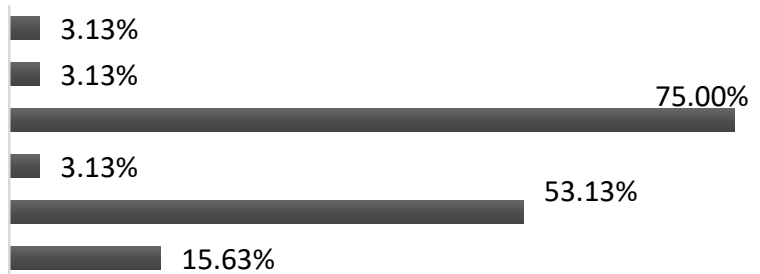

In analysis of Graph 3, we can see that the constraint Development costs, was the most marked by the respondents with $75.00 \%$ and followed by Equipment acquisition with $53.13 \%$.

In regard to the multiple-choice question, where it was requested that individuals indicate, from a common set of four other functionalities, those considered relevant with the introduction of the QR-Code on the invoice, are firstly the Electronic Payments, with $75.00 \%$ and then the Integration in the logistic systems/stocks, with $62.50 \%$. From the universe of respondents, when questioned if they consider that the QR-Code on the invoice may conflict visually with the QR-Code on the e-TaxFree invoice, $56.25 \%$ of respondents answered negatively and $37.50 \%$ of respondents answered positively.

In regard to the multiple-choice question, where it was requested that individuals indicate, from a common set of three advantages, those considered relevant with the introduction of the QRCode on the invoice, the features considered relevant to the respondents are first of all the option "It would be interesting to develop functionalities that allow electronic payment if the purchaser wishes so", with $93.75 \%$, followed by "Speed up the accounting records of the data on the invoice", with $75 \%$.

\section{FUTURE RESEARCH DIRECTIONS}

The products used in the composition of thermal paper, namely Bisphenol-A (BPA), are identified as harmful to health, and their use is therefore being regulated in several countries around the world. The European Union, through regulation (EU) no. 2235/2016 (European Commission, 2016), has legislated to ban the marketing of thermal paper products with concentrations equal to or greater than $0.02 \%$ by mass, after January $2^{\text {nd }}, 2020$. As an EU regulation, it is binding in its entirety and directly applicable to all member states. An important aspect still to be studied will be the evaluation of the minimum quality of thermal paper, due to the fact that it is the most used in terms of invoicing in the retail sector, and the evaluation of compliance with this regulation by thermal paper suppliers.

Due to the current pandemic situation, with regards to the prepared questionnaires, it has not been possible to take the necessary steps to obtain more information. It will be important at a later stage, regarding the validation of the Approach, to obtain the opinion of the different 
experts, in order to carry out a more in-depth study and enrich the present project. It is suggested that dissemination of the work done is carried out to the scientific and business community.

\section{CONCLUSION}

The fact that certain countries adopt measures of unfair tax competition or create preferential tax regimes, thus constituting a factor of distortion and injustice, was decisive for the revision of traditional tax systems. The Approach validation was carried out through semi-structured interviews and online surveys and demonstrated the added value of such an Approach in view of its aggregation and multidisciplinary nature in support of the different stakeholders, providing in a single model an overview of the situation.

Therefore, the aforementioned Approach constitutes a fundamental element for decision making, strategy definition, while assisting in the analysis of the impact that the changes will cause at the level of the processes, guiding the creation of appropriate measures and the understanding of the implicit issues to the specificity of the situation. The added value of the Approach shall be deemed to focus on: systematize knowledge; centralize information; to provide a rapid and simplified reading of information; provide important conceptual bases for the subject; summarize relevant information; highlight the measures to be taken.

\section{REFERENCES}

CMMI Institute. (2019). What is CMMI®? Obtido em 18 de 11 de 2019, de cmmiinstitute.com: https://cmmiinstitute.com/cmmi/intro

Decree-Law 28/2019. (15 de 02 de 2019). Regulates the obligations regarding the processing of invoices and other fiscally relevant documents as well as the obligations to keep books, records and their supporting documents that fall upon VAT taxpayers. Lisbon, Portugal.

Decree-Law no 198/2012. (24 de 08 de 2012). Establishes measures to control the issue of invoices; form of communication to AT; encourages the request of invoice with NIF. Lisbon, Portugal.

European Commission. (13 de 12 de 2016). Regulamento (UE) 2235. Jornal Oficial da União Europeia. Bruxelas. Obtido em 11 de 01 de 2020, de https://eur-lex.europa.eu/legalcontent/PT/TXT/PDF/?uri=CELEX:32016R2235\&from=EN

ISACA. (2019). COBIT® 2019 Framework: Introduction \& Methodology. Schaumburg, USA. doi:ISBN 978-1-60420-763-7

ISO/IEC 18004:2015. (2015). ISO/IEC 18004:2015.

ITIL. (2019). What is ITIL® 4. (1. AXELOS, Ed.) Obtido em 07 de 11 de 2019, de www.itilportugal.pt: http://www.itilportugal.pt/itil-o-que-e/

ITSM Academy, Inc. (2019). ITIL4 Training Catalog - ebook. Obtido em 17 de 11 de 2019, de www.itsmacademy.com: https://www.itsmacademy.com/about-us/

Marques, A. (2020). QR-Code na Fatura Eletrónica - Vantagens e Condicionantes. Dissertação de Mestrado, Instituto Politécnico de Setúbal, Escola Superior de Ciências Empresariais, Setúbal. Obtido em 2020

Marques, A., \& Reis, L. (2020). QR-Code nos documentos fiscalmente relevantes em Portugal. CISTI'2020 - 15ª Conferencia Ibérica de Sistemas e Tecnologías de Informacão, (pp. 17). Sevilha. Obtido em 30 de 06 de 2020

Melo, C. M. (2018). e fatura A reforma digital da AT. Implicações no crescimento da receita fiscal. Tese, Instituto Superior de Gestão- ISG, Gestão Fiscal, Lisboa. Obtido em 18 de 12 de 2019, available at https://comum.rcaap.pt/ 
Secretaria do Estado dos Assuntos Fiscais - SEAF. (04 de 07 de 2018). Plano Estratégico de Combate à Fraude e à Evasão Fiscal e Aduaneira (PECFEFA) 2018-2020.

XXI Governo. (2015). Relatório de Atividades Desenvolvidas Combate à Fraude e Evasão Fiscais e Aduaneiras. (GSEAF, Ed.) Obtido em 18 de 12 de 2019, de blogs.sl.pt: https://blogs.sl.pt/cloud/file/aa4ced447f00ac5becad3d5eeddd34cb/fiscalidadeonline/201 6/Relatorio_de_Combate_a_Fraude_e_Evasao_Fiscal_2015_GSEAF.pdf

Zhang, W. (2018). Online Invoicing System based on QR Code Recognition and Cloud Storage. Advanced Information Management, Communication, Electronic and Automation Control Conference (IMCEC 2018), (pp. 1-4). Xi'an Peihua University, Xi'an, China. 